\title{
473908 - INTER-HEMISPHERIC CEREBRAL SATURATION DIFFERENCES DURING THORACIC SURGERY WITH LATERAL HEAD POSITIONING
}

\author{
David Bracco, MD, Marie-Claude Bluteau, BEng, Roy Kazan, none, Thomas \\ Hemmerling, MD \\ Anesthesiology, McGill, Montreal, QC, Canada
}

Introduction: Absolute cerebral oximetry (FORE-SIGHTTM, CASMED, USA) is a novel method of measuring cerebral oxygen saturation (SctO2); it detects SctO2 without the need for pre-induction baseline measurement. One study showed little bilateral differences in FORE-SIGHT SctO2 measurements for cardiac patients with no known carotid disease (1). However, these results were obtained from subjects in supine position. The aim of the present study is to assess inter-hemispheric SctO2 gradients in patients undergoing thoracic surgery in the lateral position.

Methods: Local REB approval was obtained for this study. In 29 consecutive patients, SctO2 was continuously measured during lung resection in the lateral position using the FORE-SIGHT 2-channel absolute oximeter. Data points were discarded if one of the signals was unstable or not available. Data were analyzed in SAS and compared between the two hemispheres; comparisons were made between upper or lower hemisphere according to the side of surgery.

Results: A total of 29 patients (lateral position L/R = 9/20) and 941 5-min blocks were collected. After exclusion of 43 periods with no or unstable signal in one hemisphere, 898 5 -min periods were included in the final analysis. 22\% of data were prior to SLV, 59\% during SLV periods and 9\% after SLV ventilation. SctO2 of the upper hemisphere was higher in $56 \%$ of cases, equal in $18 \%$ and lower than the lower hemisphere in $26 \%$. On average, SctO2 in the upper hemisphere was $1.3 \%$ higher than the lower hemisphere (95\% CI of the mean $1.06-1.49, \mathrm{P}<0.0001$ ). When SctO2 was low, there was no significant difference. With higher values of SctO2, the upper hemisphere shows significantly higher SctO2 than the lower. The inter-hemispheric SctO2 difference increased by $0.038 \pm 0.017 \%$ for each $1 \%$ increase in SctO2 ( $<<0.03$ ).

Discussion: The lower hemisphere has generally a lower SctO2. Impaired venous return gradient and higher cerebral venous blood volume may explain these differences. References: MacLeod D, et al, Bilateral Differences in Cerebral Tissue Oxygen Saturation Monitored Using an Absolute Cerebral Oximeter in Cardiac Patients, Outcomes-The Key West Meeting 2007. 

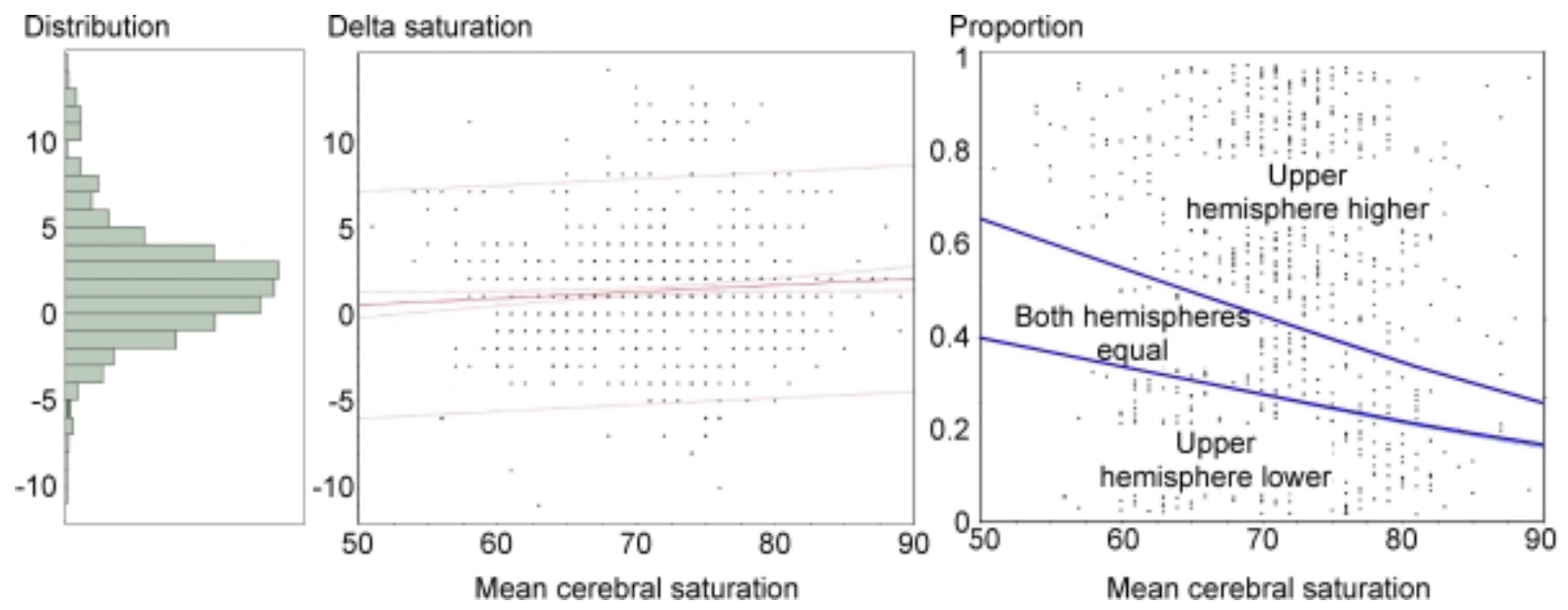